\title{
Multimedia Usage among Islamic Education Lecturers at Higher Education Institution
}

\author{
Mohd Isa Hamzah ${ }^{1}$, Rinaldi ${ }^{1} \&$ Khadijah Abdul Razak ${ }^{1}$ \\ ${ }^{1}$ Faculty of Education, Universiti Kebangsaan Malaysia, Malaysia \\ Correspondence: Mohd Isa Hamzah, Faculty of Education, Universiti Kebangsaan Malaysia, 43600 UKM Bangi, \\ Selangor, Malaysia. Tel: 603-8921-6298. E-mail: isa_hamzah@ukm.edu.my
}

Received: August 19, 2014

Accepted: November 5, 2014 Online Published: December 21, 2014

doi:10.5539/ies.v7n13p157

URL: http://dx.doi.org/10.5539/ies.v7n13p157

\begin{abstract}
This study aims to examine the level of multimedia usage among Islamic education lecturers at higher education institutions in West Sumatera, Indonesia. The participants were chosen from three types of higher institutions by using stratified random sampling. The data was collected from 250 students using questionnaires. The findings showed that the use of multimedia was moderate and there were significant differences in the use of multimedia based on gender, academic qualification, location of teaching and number of workloads. The finding also showed that there was no significant difference in the use of multimedia based on training experience. This study also found that there were significant differences in the use of multimedia based on age, type of institution and teaching experience.
\end{abstract}

Keywords: multimedia, usage, lecturers, higher educational institution, West Sumatra Indonesia

\section{Introduction}

Today, higher education lecturers are employed by universities to undertake various tasks including teaching, research and administrative jobs. However, teaching is still the main task that they should perform and this is particularly true in the case of universities in Indonesia. Here, lecturers are required not only giving lectures, but they are expected to monitor closely the intellectual enhancement of students. Lecturers as much as possible can make a sermon to be effective, relevant, and to grow in line with the time. The change is covering many aspects of teaching and learning techniques and curriculum. Conventional teaching methods that rely only on books and lectures do not guarantee the effectiveness of the teaching and learning process (J. Herrington \& A. Herrington, 1998). Ordinary teaching methods in Islamic subjects are primarily based on the book and lectures only. This inactive presentation often makes students feel tired and sleepy. The sluggishness produced in students leads them to be less receptive even of the essential points of the lecture.

Many studies has been carried out on multimedia and this studies have focus on multimedia education and how multimedia has been used to make teaching and learning more interesting, interactive and effective. Some of these studies have focused specifically on Islamic education (Wan \& Kamaruzaman, 2009). Multimedia is hypertext, audio, video, animation, simulation and interactivity that facilitate teaching and learning by allowing students to visualize and engage with the concepts being taught. Traditional teaching methods that rely only on books and lectures do not allow as much student engagement and visualization.

Many studies (Zainuddin, 1997; Said, 2001; Abdul, 2005; Abdul et al., 2006; Izham \& Attan, 2007; Wan \& Kamaruzaman, 2009) have been carried out examining the use of multimedia in the teaching environment. They found that many teachers have some idea about the benefit of multimedia aided instruction, but these same teachers lack the skills to implement it. Further, Izham and Attan (2007) found that the use of multimedia in classrooms is still quite low.

To implement multimedia aided teaching and learning, lecturers must have certain proficiencies. In this regard, Wetzel et al. (2002) found that lecturers must be proficient in three areas: first, know how to use it, second, understand the roles and capabilities of these technologies and finally, learn how to integrate them into the curriculum. It is also supported by Elias and Ali (2014) who stated that lecturers are lacking in these proficiencies due to a lack of training.

Tan (1999) noted a lack of understanding among lectures on how to integrate multimedia in teaching and 
learning is an influential aspect that contributed towards the low level of usage. Lectures seldom use multimedia in the classroom because of lack of knowledge and they are afraid of something wrong happens in the classroom while using multimedia.

Many studies were conducted to identify problems to apply multimedia in teaching (Zuraidah, 1998; Hajar, 2005; Sheingold \& Hadley, 1990). Among the problems are lack of infrastructures and multimedia equipments, inadequate numbers of multimedia software and difficulty in accessing multimedia labs. Hajar (2005) also stated that it is important and necessary availability of infrastructures and multimedia equipment is the most influential factor towards multimedia usage. Those problems influence lecturer to apply multimedia in teaching. However, Larry et al. (2001) reported that inadequate multimedia does not influence much to the multimedia usage due to lecturers rarely to use it.

In Indonesia, the interest to use multimedia for education purposes has growing. Almost every school and university in big cities in Indonesia has multimedia room. It is part of educational process for improving the student skill in information and technology. However, the usage of this multimedia is limited and not all teachers and students have the opportunity to use multimedia. It is due to inadequate equipment to cover all of the students. Only certain teachers have the opportunity such as science teachers (Asraf, 2010). For Islamic education teachers, they are prefer to use conventional method such as using books and lectures. Only certain Islamic education teachers have used cassette and CD in their classroom (Fandi, 2008).

However, the development of multimedia in Indonesia is still lag behind neighbouring countries such as Singapore, Malaysia and Thailand (Adnan \& Zamari, 2012). There are problems and obstacles that hindering lecturers to use multimedia in curriculum activities and non-curriculum activities (Arifin, 2011). Asif (2003) stated that these problems mainly related to the policy, standardization, network infrastructure and content, readiness and culture of human resources in the educational environment. Therefore, various attempts have been made by the government to encourage the use of multimedia in education especially in higher education institutions. This is seen as a very important policy and requires an integrated, systematic and sustainable strategy (Budiningsih et al., 2010). Such policy in upgrading the quality of implementation of multimedia-based education is badly needed in Indonesia (Priyanto, 2011).

Not many studies that observe the use of multimedia in higher education in Indonesia particularly in Islamic education. Islamic education is one of important components in higher tertiary education; therefore, this study will be conducted to explore the use of multimedia among Islamic lecturer in Padang West Sumatera, Indonesia. Padang has been chosen because of it consists high number of Islamic education institution. This study aims to assessing the level of multimedia usage among Islamic education lecturers in higher education institutions and to study the significance of multimedia usage based on gender, academic qualification, age, type of institution, location of teaching, teaching experience, training experience and teaching workload.

\section{Method}

\subsection{Research Design}

The study adopted descriptive research design of ex-post facto type. This type of study is suitable for the independent variables not manipulated by the researcher. It was a survey study that represents a large number of samples. The data will show the level of multimedia usage and the significance of multimedia usage based on the demographic profile of respondents.

\subsection{Target Population}

The population in this study covers all Islamic education lecturers in Padang, West Sumatra, Indonesia. The total number of Islamic education lecturers in West Sumatera is 1,709 lecturers, which scattered in various universities, institutes and Pre-universities.

\subsection{Sampling and Sample}

Sampling is conducted by a stratified random method. Stratified random method has been used because the population is heterogeneous form, which covers gender, lecturers' academic background, age, type of institution, location of teaching, teaching experience, training experience and number of workload. By using stratified random sampling, the data collected is more accurate and it represents each stratum (Brymer \& Cramer, 2005). This study has selected 250 lecturers from all Higher Learning Institutions in West Sumatera.

\subsection{Instrument}

A questionnaire was used as an instrument in this study. The questionnaire contains 2 parts (Part A and Part B). Part A includes socio-demographic of respondents. Part B is to determine the level of multimedia usage. 5-point 
Likert type scale of $1=$ never, 2 = almost never, $3=$ occasionally/sometimes, $4=$ almost every time, $5=$ every time has been used. Dependent variables in this study are the multimedia usage level. While independent variables include gender, academic qualification, age, type of institutions, location of teaching, teaching experience, training experience and the number of workloads.

\subsection{Validity of Instruments}

The validity of the instruments was approved by multimedia experts from the Faculty of Education, Universiti Kebangsaan Malaysia. The views of the experts were used to revise the items in the questionnaire.

\subsection{Reliability of the Instruments}

The reliability was measured by Alpha Cronbach as the coefficient of reliability (r). It shows the coefficient of reliability 0.91 for level of multimedia usage among lecturers. The coefficient of reliability shows that all items in the instrument were reliable and can be accepted.

\subsection{Data Collection}

In this study, a survey was conducted to collect the data. The questionnaire was administered among the sample of the research. Before they filled up the questionnaire, they were given a short brief about the study and how to answer the questionnaire.

\subsection{Data Analysis}

Data was analysed using Statistical Package for the Social Sciences Version 19.0 software (SPSS 19.0). There are two kind of analysis, descriptive and inferential analysis. Descriptive analysis described by percentage, mean and standard deviation. Percentage also was used to determine profile of respondents included gender, academic qualification, age, type of institutions, location of teaching, teaching experience and training. Meanwhile, mean and standard deviation was used to determine the multimedia usage level of Islamic lecturer. Mean of 1 to 2.33 is categorized as low level, mean of 2.34 to 3.66 is categorized as moderate level and mean of 3.67 to 5 is categorized as high level.

The inferential analysis using independent-samples T-test and one way ANOVA was conducted in this study. Independent-samples T-test has been used to determine significant differences on multimedia usage of Islamic lecturers according to gender, academic qualifications, location of teaching, training experience and workloads. One way ANOVA is used to determine significant difference on multimedia usage of Islamic lecturers according to age, type of institution and teaching experience.

\section{Results}

\subsection{Descriptive Analysis}

The data gathered were analysed using SPSS 19.0. The background of the respondents are include gender, academic qualification, age, type of institutions, location of teaching, teaching experience, and training. The demographic information is presented in Table 1.

Table 1. Profile of respondents

\begin{tabular}{llll}
\hline & background & $\mathrm{N}$ & $\%$ \\
\hline Gender & Female & 124 & 49.6 \\
& Male & 126 & 50.4 \\
Academic & Master & 132 & 52.8 \\
Qualification & Doctorate & 118 & 47.2 \\
Age & Less than 30 years & 84 & 33.6 \\
& 30 - 40 years & 101 & 40.4 \\
\multirow{3}{*}{ Type of institutions } & More than 40 years & 65 & 26.0 \\
& University & 80 & 32.0 \\
& Institute & 85 & 34.0 \\
& Pre-university & 85 & 34.0 \\
\hline
\end{tabular}




\begin{tabular}{llll}
\hline Location of teaching & Urban & 174 & 69.6 \\
& Rural & 76 & 30.4 \\
Teaching experience & Less than 10 years & 83 & 33.2 \\
& $10-20$ years & 101 & 40.4 \\
\multirow{4}{*}{ Training } & More than 20 years & 66 & 26.4 \\
& Yes & 222 & 88.8 \\
Amount of workload & No & 28 & 11.2 \\
& 2 workload or less & 116 & 46.4 \\
& More than 2 workload & 134 & 53.6 \\
\hline
\end{tabular}

Respondents from 250 lecturers showed that the composition of female and male respondents was almost same with $49.6 \%$ of female and $50.4 \%$ of male. Most of the respondents have had master degree $(52.8 \%)$ and doctorate $(47.2 \%)$. The majority of the lectures are 30-40 years old. The lecturers were enrolled across diverse institution and most of the institutions are situated in urban area.

Most of the responses come from lecturers within 10-20 years' experience in teaching (40.4\%). 88.8\% lecturers have had training in multimedia. Around $53 \%$ of the lecturers have more than two workloads.

The finding of the study about multimedia usage level of Islamic lecturer is presented in Table 3.2. Score mean is used as a tool for measuring the level. The overall level and per item of multimedia usage also describe in Table 2.

Table 2. Results of descriptive analysis on the use of multimedia

\begin{tabular}{llll}
\hline Item & Mean & $\begin{array}{l}\text { Standard } \\
\text { deviation }\end{array}$ & Level \\
\hline I use computers in teaching in the classroom & 2.94 & 0.839 & Moderate \\
I use power point in the classroom & 2.96 & 0.838 & Moderate \\
I use the video as teaching materials in the classroom & 1.87 & 0.954 & Low \\
I use the graphics (figures) as a teaching medium & 3.17 & 0.626 & Moderate \\
I use the audio facilities as teaching medium & 2.43 & 0.947 & Moderate \\
I use the animation in the teaching & 2.23 & 0.831 & Low \\
I use multimedia for difficult topics & 2.80 & 0.975 & Moderate \\
I combine the multimedia instruction for certain title & 2.83 & 0.926 & Moderate \\
\hline The overall level of use of multimedia in teaching & & & Moderate
\end{tabular}

Note. Mean 1-2.33 = low level; mean 2.34-3.66 = moderate level; mean 3.67-5 = high level.

Table 2 shows that the multimedia in the teaching of Islamic education among lecturers at higher education institutions of West Sumatra, Indonesia was in the moderate level with mean score achieved was 2.65 and the standard deviation of 0.620 although there are some things about the use of multimedia, which is low. Items at low level are using video and animation as teaching medium. The highest mean is the use of graphics as a teaching medium $($ mean $=3.17$, standard deviation $=0.626)$ whereas the lowest mean is found in the use of video as a teaching medium $($ mean $=1.87$, standard deviation $=0.954)$.

\subsection{Inferential Analysis}

\subsubsection{Multimedia Usage Based on Gender}

Table 3 shows t test results, which were conducted to determine if there is significant difference in gender regarding multimedia usage level of lecturers. 
Table 3. T-test results of multimedia usage level of lecturers based on gender

\begin{tabular}{llllll}
\hline Gender & $\mathrm{N}$ & Mean & Std. deviation & $\mathrm{t}$ & $\mathrm{p}$ \\
\hline Female & 124 & 2.45 & 0.764 & -5.552 & 0.000 \\
Male & 126 & 2.86 & 0.326 & & \\
\hline
\end{tabular}

Table three shows that there was significant difference between the multimedia usage of female and male with the value $\mathrm{t}=-5.552$ and $\mathrm{p}=0.000(\mathrm{p}<0.05)$. Based on mean obtained, male lecturers have higher mean (mean $=$ 2.86 , standard deviation $=0.764)$ compared with mean of the female $($ mean $=2.45$, standard deviation $=0.326)$. This shows that multimedia usage of male lecturers was higher than the female.

\subsubsection{Multimedia Usage Based on Academic Qualification}

Table 4 shows $t$ test results, which were conducted to determine if there is significant difference in academic qualification regarding multimedia usage level of lecturers.

Table 4. T-test results of multimedia usage level of lecturers based on academic qualification

\begin{tabular}{llllll}
\hline Academic qualification & $\mathrm{N}$ & Mean & Std. Deviation & $\mathrm{t}$ & $\mathrm{p}$ \\
\hline Master & 132 & 2.53 & 0.641 & -3.433 & 0.001 \\
Doctorate & 118 & 2.79 & 0.566 & & \\
\hline
\end{tabular}

Table 4 shows that there was significant difference between the multimedia usage of master and doctorate with the value $t=-3.433$ and $p=0.001(p<0.05)$. Based on mean obtained, lecturers with doctorate qualification have higher mean $($ mean $=2.79$, standard deviation $=0.566)$ compared with mean of the master qualification (mean $=2.53$, standard deviation $=0.641)$. This shows that multimedia usage of lecturers with doctorate qualification was higher than the master qualification.

\subsubsection{Multimedia Usage Based on Age}

Table 5 shows one-way variance analysis results, which were conducted to determine if there is significant difference in age regarding multimedia usage level of lecturers.

Table 5. ANOVA results of multimedia usage level of lecturers based on age

\begin{tabular}{llllll}
\hline Age & $\mathrm{N}$ & Mean & Std. deviation & F & $\mathrm{p}$ \\
\hline Less than 30 years & 84 & 2.38 & 0.679 & & \\
30 to 40 years & 101 & 2.64 & 0.429 & 23.940 & 0.000 \\
More than 40 years & 65 & 3.03 & 0.605 & & \\
\hline
\end{tabular}

As can be seen in Table 5, significant differences in the multimedia usage based on age were observed. When means score were determined, lecturers within age more than 40 years were the highest users of multimedia while aged 30 to 40 years were higher than aged less than 30 years.

\subsubsection{Multimedia Usage based on Type of Institutions}

Table 6 shows one-way variance analysis results, which were conducted to determine if there is significant difference in type of institutions regarding multimedia usage level of lecturers.

Table 6. ANOVA results of multimedia usage level of lecturers based on type of institutions

\begin{tabular}{llllll}
\hline Type of institutions & $\mathrm{N}$ & Mean & Std. deviation & $\mathrm{F}$ & $\mathrm{p}$ \\
\hline University & 80 & 2.96 & 0.327 & 46.161 & \\
Institute & 85 & 2.78 & 0.062 & & 0.000 \\
Pre-university & 85 & 2.19 & 0.649 & & \\
\hline
\end{tabular}


As can be seen in Table 6, significant differences in the multimedia usage based on type of institution were observed. When means score were determined, lecturers in the university were the highest users of multimedia compared to the institute and Pre-university. Multimedia usage among lecturers in institute was higher than in the Pre-university.

\subsubsection{Multimedia Usage Based on Location of Teaching}

Table 7 shows $t$ test results, which were conducted to determine if there is significant difference in location of teaching regarding multimedia usage level of lecturers.

Table 7 T-test results of multimedia usage level of lecturers based on location of teaching

\begin{tabular}{llllll}
\hline Location & $\mathrm{N}$ & Mean & Std. Deviation & $\mathrm{t}$ & $\mathrm{p}$ \\
\hline Urban & 174 & 2.94 & 0.290 & 5.131 & 0.000 \\
Rural & 76 & 2.53 & 0.681 & & \\
\hline
\end{tabular}

Table 7 shows that there was significant difference between the multimedia usage of lecturer in the rural and urban with the value $t=5.131$ and $p=0.000(p<0.05)$. Based on mean obtained, lecturers in the urban have higher mean $($ mean $=2.94$, standard deviation $=0.290)$ compared with mean of lecturer in the rural $($ mean $=2.53$, standard deviation $=0.681$ ). This shows that multimedia usage of lecturers in the urban was higher than lecturers in the rural.

\subsubsection{Multimedia Usage Based on Teaching Experience}

Table 8 shows one-way variance analysis results, which were conducted to determine if there is significant difference in teaching experience regarding multimedia usage level of lecturers.

Table 8. ANOVA results of multimedia usage level of lecturers based on teaching experience

\begin{tabular}{llllll}
\hline Teaching experience & $\mathrm{N}$ & Mean & Std. deviation & $\mathrm{F}$ & $\mathrm{p}$ \\
\hline Less than 10 years & 83 & 2.34 & 0.682 & & \\
10 to 20 years & 101 & 2.65 & 0.418 & 28.485 & 0.000 \\
More than 20 years & 66 & 3.04 & 0.584 & & \\
\hline
\end{tabular}

As can be seen in Table 8, significant differences in the multimedia usage based on teaching experience were observed. When means score were determined, lecturers within experience more than 20 years were the highest users of multimedia compared to experience 10 to 20 years and less than 10 years. Multimedia usage among lecturers within experience 10 to 20 years was higher than experience less than 10 years.

\subsubsection{Multimedia Usage based on Training}

Table 9 shows $t$ test results, which were conducted to determine if there is significant difference in training regarding multimedia usage level of lecturers.

Table 9. T-test results of multimedia usage level of lecturers based on training

\begin{tabular}{llllll}
\hline Training & $\mathrm{N}$ & Mean & Std. Deviation & $\mathrm{t}$ & $\mathrm{p}$ \\
\hline Yes & 222 & 2.66 & 0.621 & 0.101 & 0.920 \\
No & 28 & 2.64 & 0.625 & & \\
\hline
\end{tabular}

Table 9 shows that there was significant difference between the multimedia usage of lecturer in the rural and urban with the value $t=5.131$ and $p=0.000(p<0.05)$. Based on mean obtained, lecturers in the rural have higher mean $($ mean $=2.94$, standard deviation $=0.290)$ compared with mean of lecturer in the urban (mean $=$ 2.53 , standard deviation $=0.681$ ). This shows that multimedia usage of lecturers in the rural was higher than lecturers in the urban. 


\subsubsection{Multimedia Usage Based on Number of Workload}

Table 10 shows $t$ test results, which were conducted to determine if there is significant difference in number of workload regarding multimedia usage level of lecturers.

Table 10. T-test results of multimedia usage level of lecturers based on number of workload

\begin{tabular}{llllll}
\hline Number of workload & $\mathrm{N}$ & Mean & Std. Deviation & $\mathrm{t}$ & $\mathrm{p}$ \\
\hline 2 workloads & 116 & 2.75 & 0.571 & 2.689 & 0.008 \\
More than 2 workloads & 134 & 2.54 & 0.657 & & \\
\hline
\end{tabular}

Table 10 shows that there was significant difference of multimedia usage based on number of workload with the value $\mathrm{t}=2.689$ and $\mathrm{p}=0.008(\mathrm{p}<0.05)$. Based on mean obtained, lecturers with 2 workloads have higher mean $($ mean $=2.75$, standard deviation $=0.571)$ compared with mean of lecturer with more than 2 workloads $($ mean $=$ 2.54 , standard deviation $=0.657$ ). This shows that multimedia usage of lecturers with 2 workloads was higher than lecturers with more than 2 workloads.

\section{Discussion}

Findings showed that the use of multimedia among Islamic education lecturers in higher education institutions in West Sumatera, Indonesia was at the moderate level with some items were at low level. The highest mean score for the items was the use of graphic in teaching. The use of graphic in teaching is vital to facilitate the identification of objects, to classifying objects, to demonstrate the spatial relationship of an object, and helping to explain an abstract concept.

The low usage of animation (mean score of 2.23) and video (mean score 1.87) is probably because of the difficulty to access for relevant materials and the significant amount of time that must be provided in the preparation of the video and animation (Ely, 1990).

The results also showed significant differences in the use of multimedia teaching on gender. The use of multimedia among male lecturers is higher than female. This finding is supported by Abdul (2005), Larry et al. (2001) and Konan (2010) which showed the significant different levels of multimedia usage on gender. This can be explained based on the research of Gurian (2004) who showed that male's spatial ability is higher than female. They have the capacity to think about objects in three dimensions and to draw conclusions about those objects from limited information.

The findings also revealed the significant difference in the use of multimedia based on academic qualification. Lecturers with doctorate degree had a better score mean than lecturers with master's degree. Konan (2010) found that the academic qualification affected the use of multimedia. This finding is contrary to the finding of research study conducted by Zainuddin (1997) who found that the academic qualifications do not affect the level of multimedia usage. Lecturers with a doctorate qualification probably have the highest level of intellectual, creativity, insight and maturity which encouraged the challenge to use multimedia.

The finding also showed that age has influenced on the use of multimedia. Lecturers who are above 40 years old tend to use more multimedia compare to other lecturers. At this stage of life, people have higher emotional intelligence and maturity (Iskandar et al., 2009).

Facilities and infrastructures at universities and institutes tend to be more modern and complete when compared to Pre-university. Furthermore, many of pre-university situated in rural areas, which have insufficient multimedia facilities. This finding is inconsistent with Siti et al. (2002) who reported no significant difference between the use of multimedia in rural and urban areas. They noted that the use of multimedia is not dependent on location such as rural or urban, but it is related to the knowledge and attitudes towards multimedia.

Lecturers with experience of teaching more than 20 years in particular have more tendencies to learn how to teach students using multimedia. They are experienced and know how to improve their teaching quality and realize the importance of using multimedia. However, surprisingly, training experience does not give better effect to the use of multimedia. Probably this is because of the lecturers who attend these courses are only interested and enthusiastic to use multimedia in teaching and learning at an early stage after the course. However, the spirit is reduced from day to day depending on the facilities in which they work (Jamian, 2011).

Lack of time is one of obstacles and barriers in the use of multimedia among the lecturers. Yalcin et al. (2011) 
also found that lecturers need time to understand and use the technology effectively. They have no enough time because of coursework and assignments. The workload had caused significantly on the use of multimedia. As mentioned before, nowadays lecturers is not only required to teach but also burdened with various other duties such as administration, co-curriculum and society work (Arifin, 2011).

In conclusion, findings showed that the use of multimedia in teaching Islamic education among the lecturers of higher education institutions of West Sumatra as a whole is at moderate level. The use of graphics in teaching was scored the highest mean in the use of multimedia. This study would like to suggest that the workload for the lecturers to be reduced in order to increase the use of multimedia usage. The administration of Higher Education Institution and the Ministry of Education should review the workload to ensure the increase of multimedia use. Such support to reduce the workload is very important and helpful for the lecturers. Lastly, financial support in the form of grants and funds may also require encouraging lecturers in doing research on multimedia and this will promotes the use of multimedia among lecturers.

\section{References}

Abdul, M. (2005). Attitudes toward computers among teachers of information technology applications courses and communications technology (ICT) in teaching and learning (Thesis, Universiti Kebangsaan Malaysia).

Abdul, W. I. G., Kamaliah, S., \& Hasrina, M. (2006). The use of computers in teaching and learning among secondary school teachers: A case study in Penang. Kajian Malaysia, XXIV(1\&2), 203-225.

Adnan, A. H. M., \& Zamari, Z. M. (2012). Computer-Aided Self-Access Language Learning: Views of Indonesian, Malaysian \& New Zealand Practitioners. Procedia-Social and Behavioral Sciences, 67, 49-60. http://dx.doi.org/10.1016/j.sbspro.2012.11.306

Arifin, B. P. (2011). Multimedia in higher institution (Thesis, Universitas Negeri Yogya).

Asif, A. (2003). Using multimedia and cooperative learning for online teaching of signal processing techniques in communication systems. Journal of IEEE, 1-6.

Asraf, M. A. (2010). Multimedia among Islamic lecturer (Thesis, Fakultas Keguruan dan Ilmu Pendidikan. Universitas Syiah Kuala Darussalam, Indonesia).

Brymen, J., \& Cramer, D. (2005). Quantitative Data Analysis with 12 and 13: A Guide for Social Scientist. Hove: Routledge.

Budiningsih, H., Siska, M., \& Hanifah, B. (2010). Multimedia development in Islamic education (Thesis, Universitas Negeri Yogyakarta, Indonesia).

Elias, M. S., \& Ali, A. Z. M. (2014). Survey on the Challenges Faced by the Lecturers in Using Packet Tracer Simulation in Computer Networking Course. Procedia-Social and Behavioral Sciences, 131, 11-15. http://dx.doi.org/10.1016/j.sbspro.2014.04.070

Ely, D. P. (1990). Condition that facilitate the implementation of education technology innovations. Journal of Research on Computing Education, 23(2), 298-305. http://dx.doi.org/10.1080/08886504.1990.10781963

Fandi, A. (2008). Effectivity and attitude toward multimedia in higher institution: Case in Islamic university (Thesis, Universitas Muhammadiyah Surakarta, Indonesia).

Gurian, M. (2004). What Could He Thinking? How a Man's Mind Really Works. New York: St. Martin's Griffin.

Hajar, M. N. (2005). Condition facilitating the implementation of information communication technology integration in the Malaysia smart school (Ph.D thesis, Universiti Putra Malaysia, Malaysia).

Herrington, J., \& Herrington, A. (1998). Authentic assessment and multimedia: How university students respond to a model of authentic assessment. Higher Education Research and Development, 17(3), 305-322. http://dx.doi.org/10.1080/0729436980170304

Iskandar, Rohaty, M. M., \& Zuria, M. (2009). Emotional intelligence and work commitment among university lecturers in Indonesia. Journal of Malaysian Education, 34, 173-186.

Izham, H., \& Attan, N. (2007). The readiness of science teachers in the use of computer-based information technology in teaching and learning process. Journal of Technology, 46(E), 45-60.

Jamian, M., Jalil, H. A., \& Krauss, S. E. (2011). Malaysian public university learning environments: Assessing conduciveness through ICT affordances. Procedia-Social and Behavioral Sciences, 35,154-161.

Konan, N. (2010). Computer literacy level. Journal of Procedia Social and Behavioral Sciences, 2, 2567-2571. 
Larry, C., Heather, K., \& Craig, P. (2001). High access and low use of technology in Pre-university classroom: Explaining an apparent paradox. American Educational Research Journal Winter, 38(4), 813-834.

Priyanto, P. (2011). IT implementation and problems among lecturer (Thesis, Universitas Muhammadiyah Surakarta, Indonesia).

Said, D. (2001). Arabic language teaching and learning assisted by computer: the perception of Arabic language teachers in the Hulu Langat district (Thesis, Universiti Kebangsaan Malaysia, Malaysia).

Sheingold, K., \& Hadley, L. M. (1990). Accomplished teachers integrating computers into classroom practice. New York: Bank Street College.

Siti, A. H., Noraidah, S., \& Hazura, M. (2002). Comparative study of awareness, knowledge and use of ICT among teachers in urban and rural schools. Proceedings of Education Profession Seminar.

Tan, J. N. (1999). Barriers to innovation in primary school science: The case of Malaysia. Jurnal Pendidikan Guru, 12, 11-24.

Wan, N. H., \& Kamaruzaman, J. (2009). Using multimedia in teaching Islamic studies. Journal of Media and Communication Studies, 1(5), 86-93.

Wetzel, K., Zambo, R., \& Padget, H. (2002). A picture of change in technology-rich k-8 classrooms. Journal of Computing in Teacher Education, 18(1), 5-11. http://dx.doi.org/10.1080/10402454.2001.10784425

Yalcin, S. A., Yalcin, S., Sagirli, M. O., Yalcin, P., \& Koc, A. (2011). The Usage of instructional technologies by lecturers (examples of Erzincan). Procedia-Social and Behavioral Sciences, 28, 435-438. http://dx.doi.org/10.1016/j.sbspro.2011.11.083

Zainuddin, A. H. (1997). Computer usage among school administrators in Seberang Perai Selatan District (Thesis, Universiti Utara Malaysia, Malaysia).

Zuraidah, S. (1998). Factor affecting the implementation of information technology in secondary schools within the Klang Valley (Thesis, Universiti Malaya, Malaysia).

\section{Copyrights}

Copyright for this article is retained by the author(s), with first publication rights granted to the journal.

This is an open-access article distributed under the terms and conditions of the Creative Commons Attribution license (http://creativecommons.org/licenses/by/3.0/). 